\title{
Prof. Dr. Dr. h.c. Norbert Szyperski
}

\section{September 1931 - 17 May 2016}

\author{
Stefan Klein • Claudia Loebbecke
}

Published online: 21 June 2016

(C) Springer Fachmedien Wiesbaden 2016

What was meant as congratulation for his 85th birthday now has sadly become an obituary.

Nobert Szyperski was an extraordinarily benign and resourceful person who put into action what he believed in: he was a gifted speaker and teacher with a rich repertoire of captivating stories, an always curious intellectual who consciously crossed disciplinary and cultural boundaries, and an engaged and visionary scholar driven by an entrepreneurial spirit.

For him, being a professor was an approach to and mode of life even at the age of 84 . He was committed to making this world a better place. In his quest for making sense he was interested in the sciences as much as in the humanities and arts. He understood academic life foremost as a dialogue and therefore hosted the Sylt Round Table to explore current societal issues with a small group of invited experts.

Already in the 1970s, while he was holding a chair for (strategic) planning, he established a productive collaboration with colleagues from organization studies and information systems, and was Editor-in-Chief of Angewandte Informatik, predecessor of BISE, from 1971 until 1991.

With sympathies for his family and profound gratitude.

Stefan Klein, Claudia Loebbecke, and the Editorial Board of BISE

Prof. Dr. S. Klein

Interorganisational Systems Group (IOS), University of Münster, Leonardo-Campus 11, 48149 Münster, Germany

e-mail: klein@wi.uni-muenster.de

Prof. Dr. C. Loebbecke ( $\square)$

Department of Media and Technology Management, University

of Cologne, Pohligstr. 1, 50969 Cologne, Germany

e-mail: claudia.loebbecke@uni-koeln.de 